\title{
REDUÇÃO DO TEMPO DE EXECUÇÃO DE ALVENARIA DECORRENTE DE INTERVENÇÕES ERGONÔMICAS
}

\author{
Reducing the runtime of masonry resulting from ergonomic interventions \\ Gilson Morales ${ }^{1}$, André Meneghel Rando Jr ${ }^{2}$
}

Recebido em 16 de agosto de 2015; recebido para revisão em 01 de setembro de 2015; aceito em 16 de março de 2016; disponível on-line em 09 de agosto de 2016.

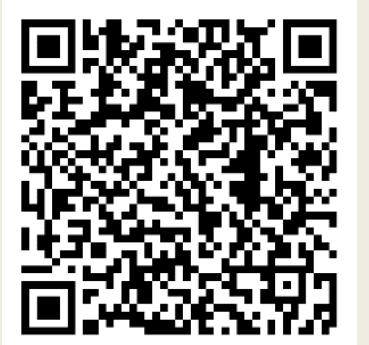

PALAVRAS CHAVE:

Construção civil;

Execução de alvenaria;

Tempo de produção;

Riscos ergonômicos.

\section{KEYWORDS:}

Civil construction;

Masonry;

Production time;

Ergonomic risks;

\section{* Contato com os autores:}

${ }^{1}$ e-mail: gilsonmorales55@gmail.com (G. Morales)

Engenheiro Civil, Pós-Doutor em Engenharia Civil pela EPUSP, Professor Associado do Departamento de Construção Civil da Universidade Estadual de Londrina (UEL).

${ }^{2}$ e-mail: andrerandojr@hotmail.com (A. M. Rando Jr )

Fisioterapeuta, Mestre em Engenharia de Edificações e Saneamento, Universidade Estadual de Londrina - UEL.
RESUMO: O objeto desse estudo foi avaliar a interferência das condições ergonômicas no tempo de execução de paredes de alvenaria de blocos cerâmicos, identificando os problemas geradores de riscos ergonômicos nessa atividade. A proposta visou introduzir adequações ergonômicas junto a esse posto de trabalho, bem como, reavaliar e comparar os resultados pós intervenção. Inicialmente, foi aplicado um questionário junto a 20 trabalhadores do setor, para identificação de zonas dolorosas. Para realizar a avaliação ergonômica, a parede em execução foi dividida em três zonas de trabalho, em função da altura e do número das fiadas. Utilizou-se foto/filmagem e o Método Rula como ferramentas de análise de risco, sendo registrado o tempo de produção. A análise dos resultados forneceu subsídios para a realização de adequações ergonômicas nos postos de trabalho, organização dos mesmos e treinamento dos colaboradores envolvidos. Foi observado, após realizadas as adequações ergonômicas, uma redução de $21 \%$ no tempo de produção da parede de alvenaria. A contribuição desse trabalho para a área da construção civil é disponibilizar medidas para melhorar a postura dos funcionários, aumentar a produtividade e reduzir o tempo de execução de paredes em alvenaria de blocos cerâmicos.

ABSTRACT: The object of this study was to evaluate the interference of ergonomic conditions at runtime of masonry walls of ceramic blocks, identifying ergonomic hazards generators problems in this activity. The proposal aimed at introducing ergonomic adjustments with this job, as well as, re-evaluate and compare the results post intervention. Initially, a questionnaire was administered with a 20 sector workers to identify painful areas. To accomplish the ergonomic evaluation, the wall was split into three work zones, depending on the height of the rows. We used photo / filming and Rula method as tools for risk analysis, and timed the production time of each row. The results provided subsidies for the realization of ergonomic adjustments in the workplace, organization of such posts and training of employees involved. Was observed after the ergonomic adjustments a $21 \%$ reduction in production time from the masonry wall. The main contribution of this research is to provide knowledge on measures to improve the position of employees, increase productivity and reduce the execution time of masonry walls of ceramic blocks. 


\section{INTRODUÇÃO}

A falta de capacitação de grande parte dos operários envolvidos em tarefas da construção civil tem sido a grande responsável por sérios problemas de saúde dos mesmos, muitos dos quais não identificados ao longo do período em que esses desenvolvem suas atividades profissionais. Muitos desses problemas só vão se agravar efetivamente em idades avançadas, quando resta muito pouco a ser feito.

Porém, muitas vezes, de forma imperceptível, os fatores de risco vão comprometendo, não apenas a saúde do operário, como também, o seu ritmo de trabalho. Um processo de trabalho inadequado, bem como a adoção de posturas inadequadas para a realização das tarefas, intensifica o risco de doenças ocupacionais ou distúrbios ocupacionais relacionados ao trabalho (DORT), levando muitos operários à incapacidade parcial ou total, comprometendo o rendimento e a produção.

A busca de melhores condições de trabalho reflete na melhoria do processo e isto se dá, muitas vezes, por meio de simples adequações. Este estudo visa quantificar a redução do tempo de execução da alvenaria em função das medidas ergonômicas cabíveis, preventivas e/ou corretivas, junto ao posto de execução de alvenaria.

Segundo Medeiros (2013), o profissional da área da ergonomia contribui para o planejamento, projeto e a avaliação de tarefas, postos de trabalho, produtos, ambientes e sistemas, possibilitando que estes sejam compatíveis com as necessidades, habilidades e limitações das pessoas envolvidas.

Partiu-se da hipótese de que, por meio de intervenções ergonômicas, é possível reduzir os fatores de risco de doenças ocupacionais, melhorar as posturas de trabalho e, em consequência disso, reduzir o tempo de execução do metro quadrado de parede de vedação em alvenaria de blocos cerâmicos.

\subsection{DISTÚRBIOS CAUSADORES DE DOENÇAS OCUPACIONAIS}

Segundo Entzel, Albers e Welch (2006) é uma característica bastante comum na construção civil a ocorrência de inúmeros distúrbios musculoesqueléticos relacionados ao trabalho em pedreiros e serventes.

Muitos desses quadros poderiam ser evitados se fossem realizadas pequenas intervenções ergonômicas nos postos de trabalho, adaptações de equipamentos e ferramentas, inserção de ferramentas de apoio e adoção de uma política de reeducação laboral por meio de treinamento dos operários.

Nem sempre se consegue atingir o rendimento esperado dos serviços porque as condições de trabalho não possibilitam a redução do seu tempo de execução. Isso pode ser causado, tanto pelas características pessoais do operário (peso corporal, alterações biomecânicas e idade), como por fatores psicossociais (baixo índice de treinamento, ferramentas inadequadas, tempo de trabalho e satisfação profissional), resultando na elevação dos fatores de riscos de lesões musculoesqueléticas (OLIVEIRA, 2004).

A incapacidade do setor da construção em identificar e intervir junto a esse tipo de ocorrência, segundo Couto (2000), favorece a incidência de DORT.

$\mathrm{O}$ alto índice de lombalgias verificado no setor se deve, particularmente, ao elevado número de ações envolvendo o trabalho braçal, três vezes maior que em funcionários administrativos. Dentre os principais fatores de risco estão o levantamento e o carregamento de cargas elevadas.

Essa sobrecarga física é a grande responsável pela deterioração da estrutura e função dos músculos ligamentares do corpo humano, agravada pela execução de tarefas que envolvem movimentos repetitivos, ausência de pausa entre ações, posturas inadequadas por tempo prolongado e invariabilidade de tarefas. As manifestações patológicas, resultantes dessas situações, tanto podem afetar uma determinada região anatômica, como pode envolver, simultaneamente, diversas áreas dos membros superiores e inferiores.

Arndt et al. (2005) afirmam que, dentre as ocorrências de doenças ocupacionais em trabalhadores da construção civil, $45 \%$ delas decorrem de transtornos musculoesqueléticos, 
provocando o comprometimento do ritmo de trabalho e reduzindo a produtividade, com constantes afastamentos do trabalhador.

$\mathrm{Na}$ atividade de execução de paredes de alvenaria, foi observado por SAAD et al. (2006) que o risco postural é maior quando o operário se desloca para buscar os blocos com o carrinho de mão.

Segundo Welch et al (1999), dentre os operários observados em seu estudo, 62\% perdeu mais de dois meses de trabalho devido a lesões na região lombar (28\%), lesões na região do pé/tornozelo (20\%), extremidades superiores (15\%), ombros (14\%) e joelho/perna/quadril (14\%). Todos esses aspectos acabam comprometendo o ritmo da obra e causam atrasos e perdas consideráveis. Adequações ergonômicas junto aos postos de trabalho, tais como, organização e reposicionamento de equipamentos e máquinas, adequação do ritmo de trabalho, implantação de sistema eficiente de locomoção de cargas e treinamento visando correções posturais dos operários podem trazer muitas melhorias ao sistema, dentre as quais, a redução do tempo de execução de tarefas pontuais e da execução como um todo. Essa última é um dos focos deste estudo.

\section{OBJETIVOS}

Por meio deste estudo, pretende-se verificar a interferência das condições ergonômicas de trabalho no tempo de produção de alvenaria de vedação em blocos cerâmicos de nove furos em um edifício residencial, padrão médio, na cidade de Londrina.

\section{CARACTERÍSTICAS DO POSTO DE TRABALHO}

Atualmente, por meio de uma gestão racional do canteiro de obras e das técnicas e processos construtivos, tem-se buscado o estabelecimento de um modelo que permita a obtenção de altos índices de produtividade e rendimento.

Por meio da otimização dos sistemas de produção, tem-se buscado a redução dos custos e uma maior integração do homem ao trabalho. O foco dessas inovações é sempre a qualidade do produto, a redução de custos e do tempo de execução.

Por um lado, aspectos antes negligenciados ou considerados pouco relevantes, como o grau de satisfação do operário, o condicionamento físico e a ocorrência de estados dolorosos, passaram a chamar atenção, haja vista a influência direta que exercem no tempo de execução das tarefas.

Tem ocorrido, atualmente, um aumento crescente no volume de trabalhos terceirizados no setor, a exemplo do que já vinha ocorrendo há muito tempo na Europa. Porém, uma questão preocupante trazida por esta prática no Brasil, é a alternativa de contratos por empreita, não havendo, em muitos casos, o estabelecimento de vínculos empregatícios com os operários, o que, segundo Barros e Mendes (2003), constitui-se em grave violação dos direitos trabalhistas.

Isso deixa o operário à mercê das consequências de um trabalho, muitas vezes mal orientado, ao término do qual o mesmo recebe os honorários referentes à produção, arcando com os problemas advindos das doenças laborais ligadas ao mesmo.

Essas ocorrências, muitas delas provocadas pelo ritmo acelerado imposto pelos prazos exíguos, levam o operário a situações de estresse em seu posto de trabalho, resultando em grave comprometimento da saúde.

O alto nível de exigência física dos trabalhadores da construção civil, ao longo da jornada diária, pode acarretar inúmeros distúrbios musculoesqueléticos, segundo Entzel, Albers e Welch (2006), que comprometem a conclusão das tarefas no tempo previsto.

Além disto, características pessoais (peso corporal, alterações biomecânicas e idade) e fatores psicossociais (baixo índice de treinamento, ferramentas inadequadas, tempo de trabalho e satisfação profissional), também representam fatores de risco de ocorrência destas lesões (OLIVEIRA, ADISSI e ARAÚJO 2004).

Esse quadro geral é agravado pelo 
manuseio inadequado das ferramentas de trabalho, o deslocamento de cargas elevadas e o seu posicionamento em locais de acesso dificultoso, exigindo um esforço demasiado e repetitivo por parte do operário para a realização dos procedimentos que fazem parte da atividade de elevação da alvenaria. Esses aspectos conflitantes acabam refletindo no tempo gasto para a produção do metro quadrado de parede.

\subsection{ASPECTOS QUE INTERFEREM NO TEMPO DE PRODUÇÃO}

Podem ser citados como fatores que interferem no tempo de produção:

\section{Aspectos físicos e psicológicos:}

- Idade;

- Sexo;

- Condição física;

- Histórico de lesão;

- Satisfação pessoal;

- Pressão e cobrança excessivas.

\section{Aspectos Biomecânicos do Trabalho:}

- Trabalho repetitivo;

- Postura inadequada;

- Sobrecarga;

- Excesso de deslocamentos.

\section{Aspectos Organizacionais e Ambientais:}

- Falta de clareza na orientação das tarefas;

- Desorganização do posto de trabalho;

- Uso de ferramentas inadequadas;

- Materiais mal posicionados;

- Falta de logística no canteiro de obra;

- Desconforto térmico;

- Excesso de ruído.
Dentre todos, um aspecto que interfere diretamente no tempo de execução das tarefas é a questão específica das posturas adotadas pelo operário na execução da alvenaria. A progressiva elevação da altura da parede impõe ao trabalhador contínuas alterações em seu posicionamento, como ilustram as Figuras 1(a,b e c).

Luttmann, Jäger e Laurig (1991) relatam que investigações eletromiográficas mostraram que, com a variação progressiva da altura da parede, as atividades mioelétricas das musculaturas da coluna e do bíceps do lado dominante se multiplicam, o que intensifica a sensação de dor e desconforto e retarda as ações empreendidas pelo operário.

Ao executar uma alvenaria, o operário segue uma sequência de atividades que interfere diretamente no tempo de execução de cada tarefa:

a. A ação inicial de pegar a argamassa no carrinho de mão ou na masseira, é feita com a colher de pedreiro na mão dominante. Para tal, quanto mais distanciada do operário ela estiver, maior vai ser o esforço empreendido por ele para pega-la e maior o tempo gasto para se deslocar ou se curvar até ela. Por outro lado, este movimento, curvando a coluna cervical, irá produzir cumulativamente um grande estresse;

b. O passo seguinte, de colocar a argamassa sobre o contra piso ou sobre o bloco já assentado, para executar a fiada seguinte, irá exigir tanto mais do operário, quanto maior a flexão de tronco que ele terá que realizar e o tempo de

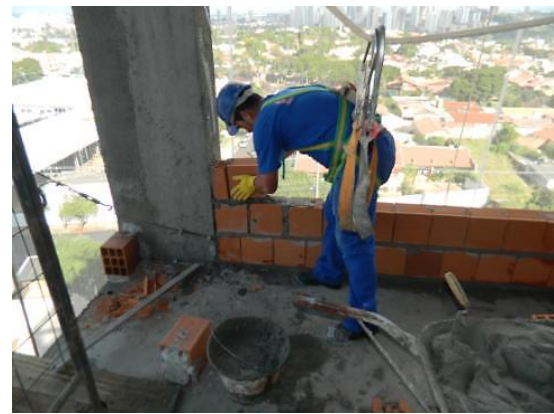

[a]

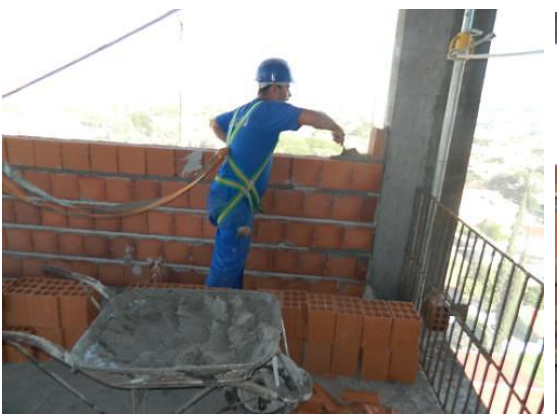

[b]

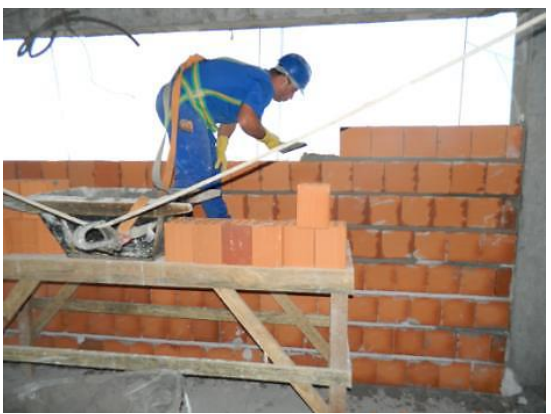

[c]

FIGURA 1: Execução das fiadas da parede em alvenaria.

FONTE: Autoria própria. 
execução será diretamente proporcional a esse esforço;

c. O mesmo ocorre ao assentar o bloco cerâmico sobre a argamassa, situação agravada pela realização do encabeçamento dos blocos, ou seja, aplicação de argamassa na sua lateral, constituindo a junta de amarração. A ação de encabeçar o bloco demandada muitas vezes é suprimida, para que haja um ganho de tempo na execução;

d. Na sequência, o bloco retido na mão não dominante é assentado, batendo-se sobre esse com a quina da colher de pedreiro, para posicioná-lo corretamente. A consistência da argamassa é um fator facilitador dessa operação, pois essa será tanto mais rápida, quanto maior a plasticidade da argamassa. Argamassas que oferecem resistência à extensão geram esforços no punho do operário, sendo causa de estados dolorosos e retardo na ação;

e. Posicionado o bloco, é removido o excesso de argamassa das juntas de amarração, com um movimento da colher de pedreiro no sentido ascendente, devolvendo-o ao carrinho de mão ou à masseira. Argamassas muito fluídas acentuam a necessidade dessa operação, causando maior desgaste do operário, maior sobrecarga do punho e maior dispêndio de tempo;

f. Finalmente, é conferido o prumo e repetidos os procedimentos citados, até o término da execução da fiada, e assim sucessivamente, até a conclusão da parede.

Ao desenvolver a ação de pegar a argamassa, o operário executa sucessivos movimentos de flexão do tronco, com exigência ergonômica da coluna lombar, bem como, do punho, cotovelo e ombro direito, como se observa na Figura 2, o que se agrava com o aumento da distância entre os dois.

Arndt et al. (2005) registram que $45 \%$ dos casos de doenças ocupacionais manifestadas em trabalhadores da construção civil decorrem de transtornos músculoesqueléticos, refletindo no tempo de produção e, até mesmo, requerendo o

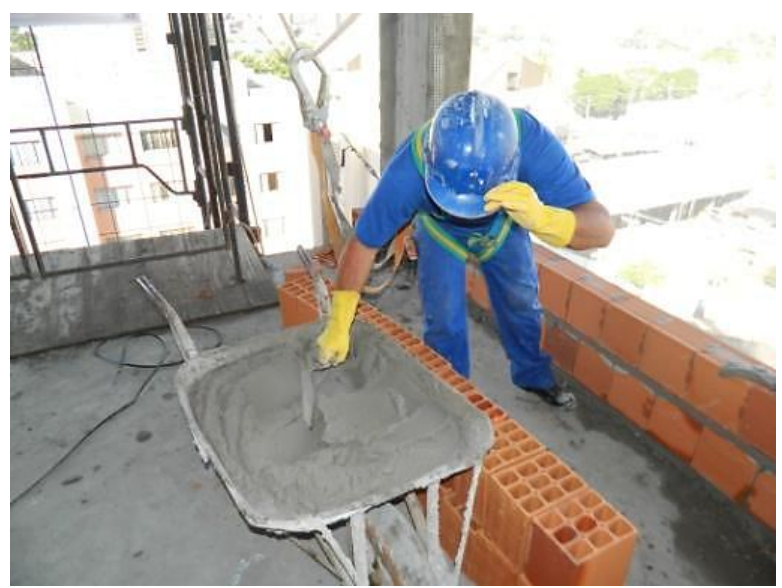

FIGURA 2: Ação do operário de se curvar para pegar argamassa.

FONTE: Autoria própria.

afastamento do trabalhador. Muitas vezes essa situação se agrava devido à necessidade de substituição do operário já treinado, por outro que não apresenta as mesmas habilidades, provocando atrasos na execução das tarefas.

Em estudos realizados nessa área, Welch et al. (1999) identificaram um percentual de 62\% referente a operários que permaneceram afastados de suas atividades devido a lesões, dentre as quais, as mais comuns foram na região lombar (28\%), na região do pé/tornozelo (20\%), nas extremidades superiores $(15 \%)$, nos ombros (14\%) e na região envolvendo joelho/perna/quadril (14\%).

É muito comum os trabalhadores envolvidos na produção de concreto, por exemplo, apresentarem dores osteomusculares, variando sua magnitude, gravidade e localização. Segundo Goldsheyder et al. (2005), mais de dois terços desses trabalhadores queixa-se de dores na coluna lombar, seguidas de dores no ombro e pescoço. Muito embora não haja identificação desses estados dolorosos ao longo da execução de um serviço na construção civil, observa-se, com frequência, que esses fatores são causadores de perda de ritmo na execução das tarefas. As condições ergonômicas de trabalho podem ser tomadas como indicadores da velocidade de execução e do rendimento na construção, sendo fatores significativos para que sejam alcançados bons níveis de qualidade e produtividade. É importante analisar quais fatores posturais, identificados no posto de trabalho, interferem no 
tempo de produção e nos índices de produtividade e qualidade, para que sejam propostas adequações.

Desse modo, o acompanhamento das práticas da construção civil por um profissional de ergonomia representa um grande desafio, principalmente quando o objetivo é a solução de questões relativas ao aspecto físico do trabalho (FRANCO, 2001).

Em muitas situações, pequenos ajustes ergonômicos são responsáveis por expressivos ganhos de tempo na execução de uma atividade.

\section{MÉTODO DE AVALIAÇÃO ERGONÔMICA}

Para verificar a interferência das condições ergonômicas de trabalho no tempo de execução de uma tarefa na produção de paredes de alvenaria, é preciso realizar um acompanhamento, passo a passo, das ações desenvolvidas.

Neste estudo, foi realizada a avaliação ergonômica do posto de trabalho utilizando o Método RULA, ferramenta de avaliação do risco de DORT, denominada Rapid Upper Limb Assessment (RULA), desenvolvida por MCATAMNEY e CORLETT (1993).

Conforme SAAD (2006), o Método RULA é adequado, particularmente, para investigações ergonômicas em locais de trabalho onde haja queixas de desordens dos membros superiores, pois permite uma análise com maior detalhamento da atividade dessas extremidades.

Trata-se de uma forma de classificar, integradamente, os riscos de doenças ocupacionais, particularmente em nível postural. A ferramenta indica uma ordem de prioridade para as intervenções, com base na perspectiva epidemiológica da incidência das patologias por meio da observação do ambiente de trabalho.

O método torna possível, sem o uso de equipamentos especiais, uma rápida avaliação das posturas desenvolvidas pelo operário, bem como, dos esforços exercidos, da repetitividade e da ocorrência de exposição a cargas externas. Utilizam-se diagramas posturais e tabelas de pontuação para indicarem o grau de exposição aos fatores de riscos. A análise é complementada pela observância da repetitividade de movimentos, da estaticidade do trabalho muscular, da força muscular empreendida, das posturas de trabalho condicionadas pelos equipamentos ou mobiliários e da ocorrência de ciclos prolongados de trabalho sem pausas.

A avaliação resulta em uma pontuação relativa à existência de fatores de risco de doenças ocupacionais e numa lista categorizada de ações que indicam o nível de intervenção necessário, após os quais, é possível realizar uma comparação quantitativa nas etapas pré e pós-intervenção ergonômica. Essas medidas visam reduzir o risco de DORT devido à carga física imposta ao operário.

O corpo humano é dividido em dois grupos diferentes, o Grupo A, que inclui os membros superiores (braço, antebraço e punho) e o Grupo B, que inclui pernas, pescoço e tronco. As observações são feitas utilizando foto/filmagem, as quais permitem identificar os ângulos dos movimentos do trabalhador, tanto do lado direito, como do lado esquerdo do corpo.

A análise se baseia no registro das diferentes posturas de trabalho, classificadas por meio de um sistema de escores, sendo atribuída uma pontuação a cada zona do corpo.

As sequências de ações dos operários foram observadas em três zonas distintas. Para tal, dividiu-se o pé direito em Zona 1 (entre a 1a e a 4 a fiadas), Zona 2 (entre a 5a e a 7ạ fiadas) e Zona 3 (entre a 8a e a 11a fiadas). A execução foi acompanhada desde a operação de pegar a argamassa, até a conclusão da alvenaria. Foram identificadas diferentes posturas dos operários na execução das fiadas, variando em função de cada zona.

Na Figura 3 está apresentada a pontuação para a angulação de tronco. As situações que envolvem maiores pontuações serão, provavelmente, aquelas responsáveis pela maior lentidão na execução das tarefas.

A pontuação final varia de 1 a 4 e permite classificar se a tarefa é aceitável; se exige um estudo mais profundo para alteração global ou se requer apenas uma adequação parcial, bem como, o grau de urgência da intervenção. Esses dados são apresentados no Quadro 1. 

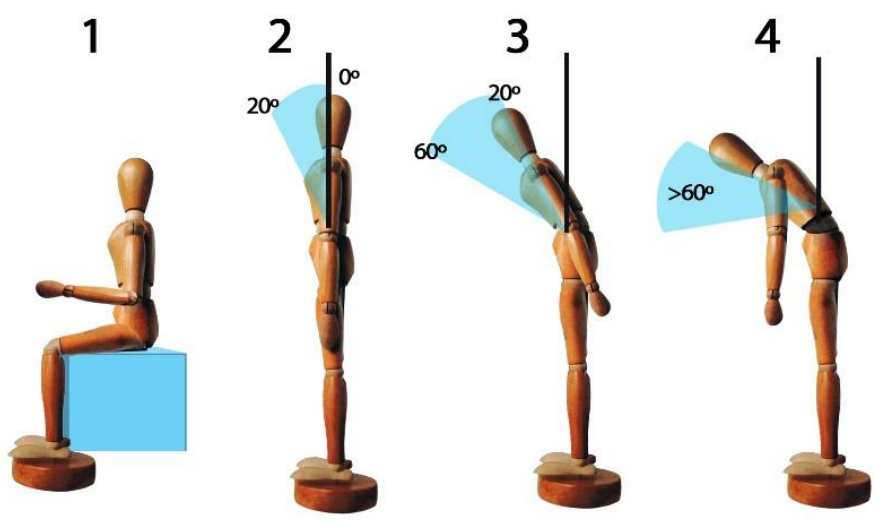

FIGURA 3: Pontuação para a angulação do tronco.

FONTE: MORALES, A. U. (2016).

\begin{tabular}{|c|c|l|}
\hline \multicolumn{2}{|c|}{ QUADRO 1: Grau de necessidade de intervenção conforme o Método RULA. } \\
\hline Nível & Pontuação & \multicolumn{1}{c|}{ Intervenções } \\
\hline 1 & 1 ou 2 & $\begin{array}{l}\text { Postura aceitável e não requer } \\
\text { intervenções. }\end{array}$ \\
\hline 2 & 3 ou 4 & Podem ser necessárias alterações da tarefa \\
\hline 3 & 5 ou 6 & Requer adequação da tarefa \\
\hline 4 & 7 & Requer alteração urgente da tarefa \\
\hline
\end{tabular}

FONTE: Autoria própria.

\subsection{A OBRA ESTUDADA}

A obra onde se realizou este trabalho foi escolhida aleatoriamente, na cidade de Londrina, Paraná, e se trata de um edifício residencial, padrão médio, com 17 pavimentos, 4 apartamentos por andar, com $81 \mathrm{~m}^{2}$ de área privativa, totalizando $140 \mathrm{~m}^{2}$ de construção, envolvendo garagens, subsolo, recepção e áreas de lazer e convívio.

\subsection{OS ASPECTOS OBSERVADOS}

O estudo envolveu o acompanhamento de todas as etapas do processo construtivo de paredes de alvenaria de vedação em blocos cerâmicos de 9 furos (altura $14 \mathrm{~cm}$, largura de $11,5 \mathrm{~cm}$ e comprimento de $24 \mathrm{~cm}$ ) e os movimentos desenvolvidos pelo operário na execução de cada atividade. O sistema construtivo observado se compõe de estrutura em concreto armado e vedação em paredes não estruturais em blocos cerâmicos. Para tal, foram empregados os equipamentos e as ferramentas pertinentes ao ofício e usuais nesta atividade, tais como, colher de pedreiro, fio de nylon, esquadro de pedreiro, escantilhão, nível de bolha, nível de mangueira, prumo de face, prumo de centro, trena, martelo, régua, marreta, carrinho de mão, betoneira, entre outros.

As ações desenvolvidas dizem respeito às atribuições do pedreiro na construção civil, particularmente, nesse caso, a execução do trabalho de alvenaria, guiando-se por desenhos e esquemas, verificando as características das obras expressas nas plantas e especificações técnicas.

A primeira atividade observada é a marcação ou locação da alvenaria, segundo o eixo da obra, seguida da colocação da primeira fiada da parede de alvenaria, com a marcação dos vãos. Para tal, são utilizados: esquadro, régua, níveis de mangueira e de bolha, linhas de nylon e prumo.

O nivelamento e o prumo da parede, segundo Thomaz et al. (2009), deve ser verificado a 
cada duas ou três fiadas por meio do prumo de face, régua e nível de bolha. Deve ser dado cuidado especial na fiada posicionada imediatamente dos vãos de janelas. Por outro lado, o alinhamento e o prumo devem ser conferidos com extremo rigor nas laterais dos vãos das portas e janelas. Isso implica na repetição de movimentos que solicitam diversas partes do corpo.

Após a elevação dos cantos da parede, o operário deve fixar e esticar uma linha entre eles, fiada por fiada, para se garantir o prumo e a horizontalidade das fiadas (NBR 8545 - ABNT, 1984).

O período de observação e registro de dados foi de três meses, no período das $14 \mathrm{~h} 00 \mathrm{~m}$ às $17 \mathrm{~h} 00 \mathrm{~m}$, para que fossem asseguradas as características do posto de trabalho, como temperatura, ventos incidentes, entre outros. Da mesma forma, visou-se manter as condições que interferissem na disposição física do operário para não comprometer as análises de desempenho e do tempo de execução.

\section{RESULTADOS}

Dentre os aspectos observados, ocorreram movimentos repetitivos para membros superiores, associados à flexo-extensão de punho e cotovelo, com abdução de ombros ao longo das ações. Isto pode acarretar inflamações tendíneas e problemas articulares que causam o comprometimento, parcial ou total do operário, por um tempo indeterminado, em função da gravidade patológica, causando redução em seu ritmo de trabalho.

Com relação às ocorrências dolorosas relatadas pelos operários, constam as originadas por flexão e rotação de coluna, com extensão dos membros inferiores, principalmente nas Zonas 1 e 3. Nesses casos, a flexão de coluna ocorreu em todo o ciclo de trabalho, o que pode levar a sérios danos da coluna lombar. Na Zona 1, a repetitiva flexão de joelhos foi um fator de estresse muscular e risco para as articulações dos membros inferiores.

Constatou-se que, na maior parte da jornada de trabalho, o operário permaneceu em pé, numa postura altamente fatigante, já que a musculatura dos membros inferiores e eretores da coluna são utilizados excessivamente. Isso pode comprometer a circulação, já que leva o coração a exercer maior esforço para o bombeamento do sangue para as extremidades do corpo.

Os resultados do Método RULA, utilizado para a identificação de riscos, indicaram que as três zonas estudadas apresentaram índice final 4, o que indica a necessidade imediata de mudanças no posto de trabalho para se reduzir o risco de doenças ocupacionais.

As Zonas 1 e 3 apresentaram características semelhantes, devido às posturas adotadas pelo operário, apresentando o mesmo risco ergonômico. A Zona 2, mesmo tendo apresentado menor risco, pelo fato do trabalhador não flexionar excessivamente o tronco, igualou-se às demais, porque ocorreu intensa flexão da coluna na ação de pegar a argamassa no carrinho de mão.

$\mathrm{Na}$ execução da fiada, por exemplo, ao estender a argamassa de assentamento sobre a superfície horizontal da fiada e na face lateral do bloco a ser assentado, o operador pressionava esse com forte pressão para nivelar a camada e conduzilo a sua posição definitiva. Esses movimentos foram os que mais solicitaram os membros superiores, associados à flexo-extensão de punho e cotovelo, com abdução de ombros.

Concluindo, nas três zonas estudadas foi identificada a necessidade de intervenções e adequações ergonômicas. Para tal, foram indicadas as seguintes medidas:

- Posicionamento da masseira sobre plataforma com altura regulável;

- Utilização de andaime com base de altura regulável;

- Transporte dos blocos cerâmicos por meio de um carrinho com rodas;

- Posicionamento dos blocos em altura fácil de alcançar sem flexões;

- Organização do posto de trabalho;

- Treinamento postural individual dos operários. 


\subsection{AVALIAÇÃO PÓS-INTERVENÇÃO}

Utilizando-se novamente o Método RULA, constatou-se uma redução na pontuação final das três zonas estudadas, sendo que na Zona 10 índice final 4, anterior às intervenções, passou para 2, para ambos os lados do corpo. Na Zona 2, o índice para o lado direito passou de 4 para 3 e para o lado esquerdo, passou de 4 para 2. Já para a Zona 3, ambos os lados do corpo apresentaram uma redução no índice de risco de 4 para 3.

A redução no tempo de execução, após as intervenções ergonômicas, pode ser observada no Quadro 2.

As Figuras 4, 5 e 6 apresentam comparações entre os tempos de produção inicial ou padrão, e o tempo de execução da fiada após as intervenções ergonômicas, em cada zona estudada. Por fim, na Figura 7 tem-se a redução total do tempo de produção por zona estudada.

\begin{tabular}{|c|c|c|}
\hline \multicolumn{3}{|c|}{ QUADRO 2: Redução do tempo de produção após as intervenções. } \\
\hline ZONA & FIADAS CONSTITUINTES & $\begin{array}{c}\text { REDUÇÃO DO TEMPO EXECUÇÃO } \\
(\%)\end{array}$ \\
\hline 1 & 1 à à 4a & 9,6 \\
\hline 2 & 5 à à 7ạ & 25,6 \\
\hline 3 & 8 à 11a & 24,5 \\
\hline Total & 1 a à 11a & 20,2 \\
\hline
\end{tabular}

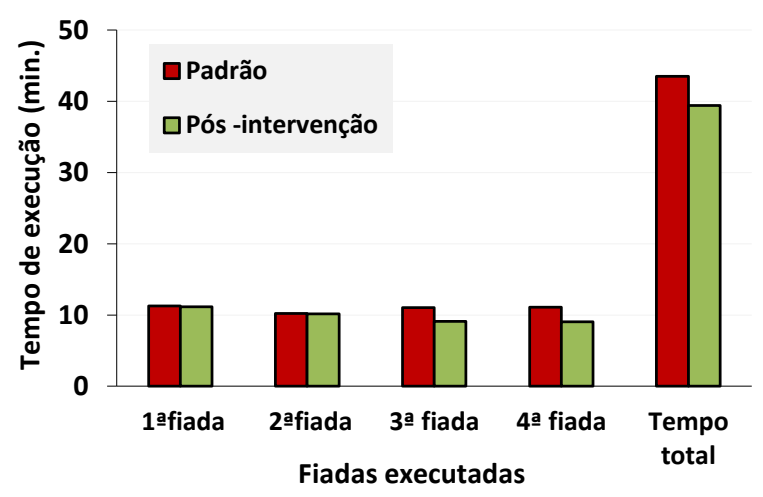

FIGURA 4: Comparação entre os tempos de produção para a Zona 1.

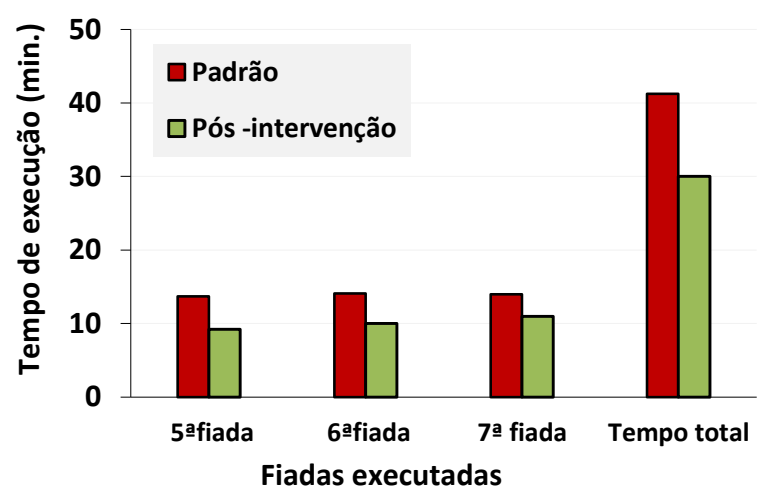

FIGURA 5: Comparação entre os tempos de produção para a Zona 2.

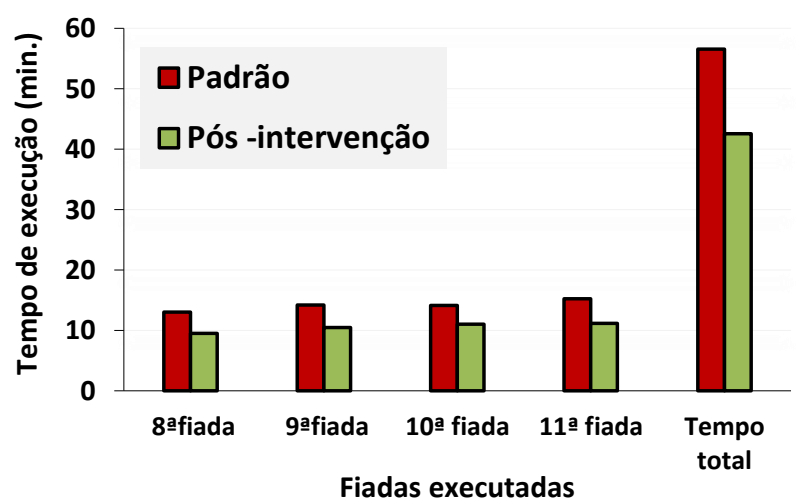

FIGURA 6: Comparação entre os tempos de produção para a Zona 3.
FONTE: Autoria própria.

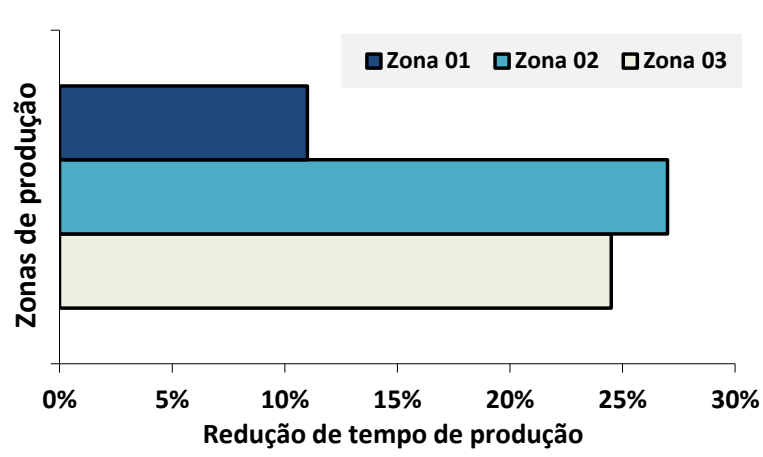

FIGURA 7: Redução no tempo de produção por zona. FONTE: Autoria própria. 


\section{CONCLUSÕES}

Uma das limitações encontradas nesse tipo de intervenção é garantir a continuidade nas correções posturais sugeridas para os operários, pois os mesmos apresentam vícios de postura já incorporados e bastante sedimentados. Quanto às intervenções junto ao posto de trabalho, acreditase que estas serão mantidas em virtude dos resultados obtidos em termos de rendimento da produção.

É importante destacar, conforme Medeiros (2013), que a adoção de pausas frequentes para descanso pelo operário que executa algum tipo de tarefa na construção civil também pode contribuir para a redução da incidência de disfunções musculoesqueléticas e aumentar a produtividade.

O resultado obtido por meio desse estudo foi bastante promissor, registrando-se a redução no tempo total de execução da parede de alvenaria da ordem de 20\%, confirmando as expectativas referentes a essas intervenções ergonômicas.

\section{REFERÊNCIAS BIBLIOGRÁFICAS}

ARNDT, V.; ROTHENBACHER, D.; DANIEL, U.; ZSCHENDERLEIN, B.; SCHUBERTH,S.; BRENNER,H. Construction work and risk of occupational disability: a ten year follow up of 14474 male workers. Occup Environ Med, 62: 559-566. 2005.

ASSOCIAÇÃO BRASILEIRA DE NORMAS TÉCNICAS. NBR 8545: Execução de Alvenaria sem Função Estrutural de Tijolos e Blocos cerâmicos. Rio de Janeiro, 1984.

BARROS, P. C. R; MENDES, A. M. B. M. Sofrimento psíquico no trabalho e estratégias defensivas dos operários terceirizados da construção civil. PsicoUSF, vol.8, no.1, p.63-70. jun. 2003.

COUTO, H. A. Novas perspectivas na abordagem preventiva das LER/DORT: o fenômeno LER/DORT no Brasil: natureza, determinantes e alternativas das organizações e dos demais atores sociais para lidar com a questão. Belo Horizonte, Ergo, 2000.

ENTZEL, P.; ALBERS, J.; WELCH, L. Best practices for preventing musculoskeletal disorders in masonry: stakeholder perspectives. Applied Ergonomics. 2006.
FRANCO, E. de M. Gestão do conhecimento na construção civil: uma aplicação dos mapas cognitivos na concepção ergonômica da tarefa de gerenciamento dos canteiros de obras. 2001. 252p. Tese de Doutorado (Engenharia de Produção). Universidade Federal de Santa Catarina, Santa Catarina. 2001.

GOLDSHEYDER, D.; NORDIN, m.; WEINER, S.; HIEBERT,R. Musculoskeletal symptom survey among mason tenders. American Journal of Industrial Medicine, v. 42, p. 384-396, 2005.

LUTTMANN, A.; JAGËR, M.; LAURIG, W. Task analysis and electromyography for bricklaying at different wall heights. International Journal of Industrial Ergonomics, v. 8 , p. $237-245,1991$

MC ATAMNEY, L.; CORLETT. E. N. RULA: a survey method for the investigation of work- related upper limb disorders. Applied ergonomics. v. 24, 1993.

MEDEIROS, D. M. A importância da ergonomia na construção civil: uma revisão. Artigo apresentado ao curso de Especialização em Ergonomia, Saúde e Trabalho. Centro de Estudos Avançados e Formação Integrada, Goiânia, 2013.

MORALES, A.U. (2016)

OLIVEIRA, D. E. S.; ADISSI, J. O.; ARAÚJO, N. M. C. Vestimenta de trabalho para a construção civil: a opinião do usuário. In: XXIV Encontro Nacional de Engenharia de Produção. Anais... Florianópolis, 2004.

SAAD, V. L.; XAVIER, A. A. P.; MICHALOSKI, A. O. Avaliação do risco ergonômico do trabalhador da construção civil durante a tarefa do levantamento de paredes. In: XIII SIMPEP. Anais... Bauru, 2006.

THOMAZ, E; MITIDIERI FILHO, C. V.; CLETO, F. R.; CARDOSO, F. F. Código de práticas no 01: alvenaria de vedação em blocos cerâmicos. Publicação do Instituto de Pesquisas Tecnológicas do Estado de São Paulo - IPT, São Paulo, 2009.

WELCH, L. S.; Katherine L. HUNTING, K.; NESSELSTEPHENS, L. Chronic Symptoms in Construction Workers Treated for Musculoskeletal Injuries. American Journal of Industrial Medicine, 36: 532-540, 1999. 